\title{
Sub-acute toxicity study in female ICR mice following repetitive intramuscular injection of cervical cancer vaccines
}

\author{
Seol-Hee Moon ${ }^{1}$, Du-Yeol Kim ${ }^{1}$, Jung-Min Lee ${ }^{1}$, Hee-Won Park ${ }^{1}$, Hye-Yeong Lee ${ }^{1}$, Yong- \\ Hoon Lee ${ }^{1}$, Jaesung Lee ${ }^{2}$, Jiwon Jung ${ }^{2}$, Min-Ju Kim², Kyoung-Baek Choi ${ }^{2}$, Yu-Kyoung $\mathrm{Oh}^{3}$, \\ Young-Bong $\mathrm{Kim}^{4}$, Sujeong $\mathrm{Kim}^{2}$, Seung Min $\mathrm{Oh}^{5}$ \\ ${ }^{1}$ Biotoxtech Co. Ltd., Ochang Scientific Industrial Complex, Cheongju; ${ }^{2}$ Institute of Bioinnovation Research, R\&D Center, \\ Kolon Life Science Inc., Seoul; ${ }^{3}$ College of Pharmacy, Seoul National University, Seoul; ${ }^{4}$ Department of Animal Biotechnology, \\ Konkuk University, Seoul; ${ }^{5}$ Department of Nanofusion Technology, Hoseo University, Asan, Korea
}

\begin{abstract}
Objectives The sub-acute toxic effects following repetitive intramuscular injection of two cervical cancer vaccines newly developed against human papillomaviruse (HPV)16/58/18 and HPV 16 were investigated in female ICR (CrljOri: $\mathrm{CD}_{1}$ ) mice, and the no-observedadverse-effect-level (NOAEL) of the cervical cancer vaccines was estimated.

Methods Female ICR mice ( $n=15$ in each group) were exposed to a 1:1 mixture of two cervical cancer vaccines by repetitive intramuscular injection (once a week, 5 times) for 5 weeks. Mortality, body weight, organ weight, hematological/biochemical parameters, and histopathological effects were examined at different concentrations $\left(0,1 \times 10^{8}, 5 \times 10^{8}\right.$, and $2.5 \times 10^{9}$ copies/animal) of the cervical cancer vaccines.

Results The cervical cancer vaccines did not show toxic responses for body weight, absolute/relative organ weight, hematological/biochemical parameters, or histopathological parameters.

Conclusions Female ICR mice exposed to vaccines for cervical cancer did not show any toxic response. We suggest that a NOAEL of the vaccine following repetitive intramuscular injection for 5 weeks is $>2.5 \times 10^{9}$ copies/animal.
\end{abstract}

Keywords Cervical cancer vaccine, Female ICR mice, Repetitive intramuscular injection.

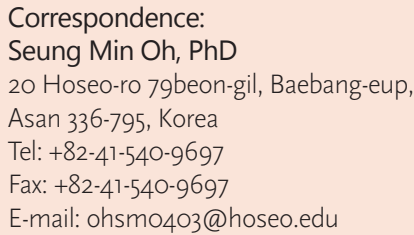

Correspondence: Seung Min Oh, PhD 20 Hoseo-ro 79beon-gil, Baebang-eup, Asan 336-795, Korea Tel: +82-41-540-9697 Fax: +82-41-540-9697 E-mail:ohsmo403@hoseo.edu

Received: October 14, 2014 Accepted: December 15, 2014 Published online: December 30, 2014

This article is available from: http://e-eht.org/

\section{Introduction}

Cervical cancer shows the seventh highest incidence rate of malignant cancers in Korean women. The sexually transmitted infection of human papillomaviruses (HPVs) has been established as the major causative agent of cervical cancer $[1,2]$. HPVs have been found in more than 150 viruses [ 3 ]. The highrisk types of HPV are 16, 18, 31, 33, 35, 39, 45, 51, 52, 56, 58, $59,68,69,73$, and 82 , while the low-risk types of HPV are 6,11 , 42,43 , and $44[4,5]$. High-risk HPV types have been found in more than $90 \%$ of cervical carcinomas or intraepithelial neopla- sia, and, in particular, two HPV types (16 and 18$)$ are responsible for about $70 \%$ of cervical cancers $[6,7]$.

Vaccination is the most effective means of preventing HPV infectious diseases [8]. Several HPV vaccines have been developed, and two cervical cancer vaccines (Gardasil ${ }^{\Phi}$ and Cervar$\mathrm{ix}^{\otimes}$ ) have obtained Food and Drug Administration approval in the USA [9]. Gardasil ${ }^{\otimes}$ for girls and boys is a quadrivalent vaccine against HPV 6/11/16/18 and Cervarix ${ }^{\odot}$ for girls only is a bivalent vaccine against HPV 16/18 [9]. The distinct efficacy of two vaccines on HPV infectious diseases was confirmed in large randomized clinical trials [10-14]. However, adverse effects of 
HPV vaccines, such as vasovagal syncope, venous thrombosis, pulmonary embolism, and amyotrophic lateral sclerosis, have been reported in several studies, although it is difficult to infer clear causal associations between HPV vaccines and adverse effects $[15,16]$. Therefore, it is important to evaluate the safety of newly developed vaccines for cervical cancer.

In this study, we investigated the sub-acute toxic effects in female ICR mice following repetitive intramuscular injection of new cervical cancer vaccines, i.e., Ac-HERV-16-58-18 L1 and Ac-HERV-LANPSS-E6E7, which target HPV 16/58/18 and HPV 16, respectively. The no-observed-adverse-effect-level (NOAEL) was also evaluated.

\section{Materials and Methods}

\section{Materials}

Two vaccines for cervical cancer were manufactured by Kolon Life Science Inc. (Gwacheon, Korea): Ac-HERV-16-58-18 L1 and Ac-HERV-LAMPss-E6E7 were developed against HPV types $16 / 58 / 18$, and HPV 16, respectively. The vaccines were suspended in Dulbecco's phosphate-buffered saline (DPBS), and stored at $3.5-6.0^{\circ} \mathrm{C}$ until administration to mice. A 1:1 mixture of the two vaccines (Ac-HERV-16-58-18 L1 and Ac-HERVLAMPss-E6E7) was injected into female ICR mice.

\section{Animals}

Because cervical vaccines are administrated in women only, female ICR mice were used to examine the toxic response of cer- vical vaccines. Specific pathogen-free female ICR mice ( 5 weeks old, 19.4-23.6 g) were purchased from Orient Bio Inc. (Seongnam, Korea). They were maintained in an environmentally controlled room under standard conditions of temperature of 21.2$23.9^{\circ} \mathrm{C}$, relative humidity of $40.7-70.2 \%$, air ventilation of $10-15$ times/hr, and a 12-hour light/dark cycle of 150-300 lux. The animals were fed with standard pellet (Harlan Laboratories, Indianapolis, IN, USA) and filter-sterilized tap-water ad libitum. All animals were housed for a 6-day acclimation period. During this period, each animal was observed once a day for health conditions and body weights were measured. Female mice were distributed into four groups (G1: control group; G2: $1 \times 10^{8}$ copies/animal; G3: $5 \times 10^{8}$ copies/animal; G4: $2.5 \times 10^{9}$ copies/animal) by stratified random sampling based on body weight, with each group containing fifteen mice (Table 1). The animals were ethically handled according to the agreed guidelines for the Biotoxtech Co., Ltd (Cheongju, Korea).

\section{Experimental Design and Administration}

A 1:1 mixture of two vaccines $\left(1 \times 10^{8}\right.$ copies/animal, $5 \times 10^{8}$ copies/animal, and $2.5 \times 10^{9}$ copies/animal) was administered by repetitive intramuscular injection using a 26-gauge needle once a week for 5 weeks. A control group was injected with DPBS only. Ten female mice were euthanized for the assessment of hematology, blood biochemistry, organ weight, and necropsy/histopathological findings. The test was performed following Good Laboratory Practice according to the "Guidelines for Toxicity Tests of Drugs and Related Materials” provided by the Korea Food and Drug Administration.

Table 1. Organ weight in female ICR mice treated with cervical cancer vaccines

\begin{tabular}{lccrr}
\hline $\begin{array}{l}\text { Group } \\
\text { (copies/animal) }\end{array}$ & G1 (0) & G2 $\left(1 \times 10^{8}\right)$ & G3 $\left(5 \times 10^{8}\right)$ & G4 $\left(2.5 \times 10^{9}\right)$ \\
\hline Body weight & $28.6 \pm 3.0$ & $29.9 \pm 2.0$ & $28.8 \pm 2.5$ & $28.3 \pm 2.5$ \\
$\quad$ Brain & $0.469 \pm 0.029(1.651 \pm 0.152)$ & $0.498 \pm 0.031(1.669 \pm 0.128)$ & $0.482 \pm 0.034(1.681 \pm 0.154)$ & $0.489 \pm 0.036(1.737 \pm 0.193)$ \\
Pituitary & $0.002 \pm 0.001(0.007 \pm 0.002)$ & $0.002 \pm 0.001(0.008 \pm 0.002)$ & $0.002 \pm 0.001(0.007 \pm 0.002)$ & $0.002 \pm 0.001(0.008 \pm 0.001)$ \\
Heart & $0.140 \pm 0.010(0.491 \pm 0.036)$ & $0.144 \pm 0.020(0.479 \pm 0.047)$ & $0.148 \pm 0.012(0.515 \pm 0.034)$ & $0.139 \pm 0.013(0.491 \pm 0.034)$ \\
Lung & $0.166 \pm 0.015(0.582 \pm 0.060)$ & $0.186 \pm 0.024(0.623 \pm 0.073)$ & $0.176 \pm 0.017(0.612 \pm 0.062)$ & $0.170 \pm 0.015(0.602 \pm 0.051)$ \\
Liver & $1.405 \pm 0.172(4.920 \pm 0.393)$ & $1.485 \pm 0.217(4.948 \pm 0.441)$ & $1.422 \pm 0.136(4.950 \pm 0.453)$ & $1.390 \pm 0.194(4.900 \pm 0.479)$ \\
Spleen & $0.114 \pm 0.034(0.395 \pm 0.091)$ & $0.132 \pm 0.044(0.435 \pm 0.116)$ & $0.148 \pm 0.045(0.512 \pm 0.140)$ & $0.137 \pm 0.041(0.481 \pm 0.119)$ \\
Kidney & $0.377 \pm 0.045(1.319 \pm 0.117)$ & $0.382 \pm 0.043(1.278 \pm 0.125)$ & $0.378 \pm 0.028(1.321 \pm 0.145)$ & $0.382 \pm 0.042(1.350 \pm 0.140)$ \\
Adrenal & $0.010 \pm 0.002(0.037 \pm 0.005)$ & $0.011 \pm 0.002(0.036 \pm 0.005)$ & $0.011 \pm 0.001(0.040 \pm 0.006)$ & $0.011 \pm 0.002(0.040 \pm 0.007)$ \\
Ovary & $0.010 \pm 0.003(0.034 \pm 0.011)$ & $0.012 \pm 0.004(0.040 \pm 0.011)$ & $0.011 \pm 0.002(0.038 \pm 0.007)$ & $0.011 \pm 0.005(0.037 \pm 0.015)$ \\
Uterus & $0.131 \pm 0.058(0.465 \pm 0.215)$ & $0.138 \pm 0.071(0.455 \pm 0.212)$ & $0.138 \pm 0.053(0.476 \pm 0.178)$ & $0.141 \pm 0.077(0.503 \pm 0.291)$ \\
\hline
\end{tabular}

Values are expressed as the mean \pm standard deviation.

Values in parentheses are relative organ weights (organ weight per body weight, \%).

No. of animals in body weight of each group $=15$ female mice.

No. of animals in organ weight of each group $=10$ female mice.

Female mice in the G1 group were treated with Dulbecco's phosphate-buffered saline only. 


\section{Organ Weights, Clinical Signs, and Mortality}

All animals were observed at least twice daily for any clinical signs of toxicity (behavioral pattern: salivation, fur, lethargy, and sleep, changes in physical appearance, injury, pain, and signs of illness) and mortality by macrograph during the experimental period. All animals were monitored for body weight changes once a week after administration.

\section{Histopathological Effects}

At the conclusion of the 5-week experiment, food was withheld for 4-hour and the mice were anesthetized by isoflurane inhalation. After blood collection, female mice were sacrificed by exsanguination of the abdominal aorta. Brain, pituitary, heart, lung, liver, spleen, kidney, adrenal gland, ovary, and uterus were carefully removed and weighed for absolute/relative organ weights. The organs were fixed in a $10 \%$ formalin solution, embedded in paraffin, and stained with hematoxylin and eosin for histopathological examination.

\section{Hematological and Serum Biochemical Parameters}

Prior to necropsy, blood was drawn from the inferior vena cava using a syringe with a 24-gauge needle. One portion of the blood was treated with ethylenediaminetetraacetic acid and analyzed for total red blood cell count (RBC), hemoglobin concentration ( $\mathrm{Hgb})$, hematocrit (Hct), mean corpuscular volume (MCV), mean corpuscular hemoglobin $(\mathrm{MCH})$, mean corpuscular hemoglobin concentration (MCHC), platelet (PLT) count, total white blood cell count (WBC), and differential leukocyte percentage (neutrophils (NEUT), lymphocytes (LYMPH), monocytes (MONO), eosinophils (EOS), and basophils (BASO)) using a hematological autoanalyzer (MS9-5; Melet Schloesing Lab., Osny, France). Another blood sample was treated with sodium citrate for blood clotting parameters prothrombin time (PT) and activated partial thromboplastin time (APTT) using an autocoagulation analyzer (Coapresta 2000; Sekisui Medical Co., Tokyo, Japan). Serum from one remaining blood sample was obtained by centrifuging at 3,000 rpm for 10 minutes, and was used for serum biochemical analysis. Alanine aminotransferase (ALT), aspartate aminotransferase (AST), alkaline phosphatase (ALP), glucose (GLU), blood urea nitrogen (BUN), creatinine (Crea), total bilirubin (T-Bili), total cholesterol (T-Chol), triglycerides (TG), total protein (TP), albumin (Alb), albumin/ globulin $(\mathrm{A} / \mathrm{G})$ ratio, phosphorus $(\mathrm{P})$, and calcium $(\mathrm{Ca})$ were analyzed using a biochemistry autoanalyzer (Hitachi 7060; Hitachi, Tokyo, Japan).

\section{Statistical Analysis}

Statistical analysis was performed using SAS version 9.3 (SAS Institute Inc., Cary, NC, USA). Data of body weight, organ weight, and hematological and biochemical parameters in female mice exposed to vaccines for 5 weeks were expressed as the mean \pm standard deviation, and were analyzed for homogeneity using Barlett's test. Tests of significance between the four groups were performed using Dunnett's $t$-test after ANOVA for homogeneous data or using the Kruskal-Wallis test for non-homogeneous data. A $p$-value of $<0.05$ was considered significant.

\section{Results}

\section{Clinical Signs, Mortality, and Effect on Body and Organ Weight}

There were no significant changes in body weight changes or food consumption in any treated group compared to the control group (Figure 1). As shown in Table 1, absolute and relative organ weights did not show a significant change in any treated group compared to the control group.

\section{Hematological and Serum Biochemical Parameters}

In the hematological analysis ( $\mathrm{RBC}, \mathrm{Hgb}, \mathrm{Hct}, \mathrm{MCV}, \mathrm{MCH}$, $\mathrm{MCHC}, \mathrm{PLT}$, and $\mathrm{WBC}$ ), and differential leukocyte counting (NUT, LYMPH, MONO, EOS, BASO), the treated groups showed no significant changes compared to the control groups (Table 2). The blood clotting parameters (PT and APTT) did not show a significant difference between the control and treated groups (Table 2).

As shown in Table 3, serum biochemical analysis (ALT, AST, ALP, GLU, BUN, Crea, T-Bili, T-Chol, TG, TP, Alb, P and Ca) showed no significant difference between the control and treated groups. However, the $\mathrm{A} / \mathrm{G}$ ratio in the vaccine-treated groups G3 and G4 showed a significant decrease compared to G1.

\section{Histopathological Effects}

As shown in Table 4, repetitive muscular injection of vaccines induced several histopathological signs, including mononuclear cell infiltration and mineralization (myofiber). However, animals in the control group showed no symptoms at the site of injection.

The histopathological effects on major organs (kidney, parathyroid gland, salivary gland, spleen, thyroid, etc.) were investigated in G1 and G4 (Table 4). Several animals showed histo- 

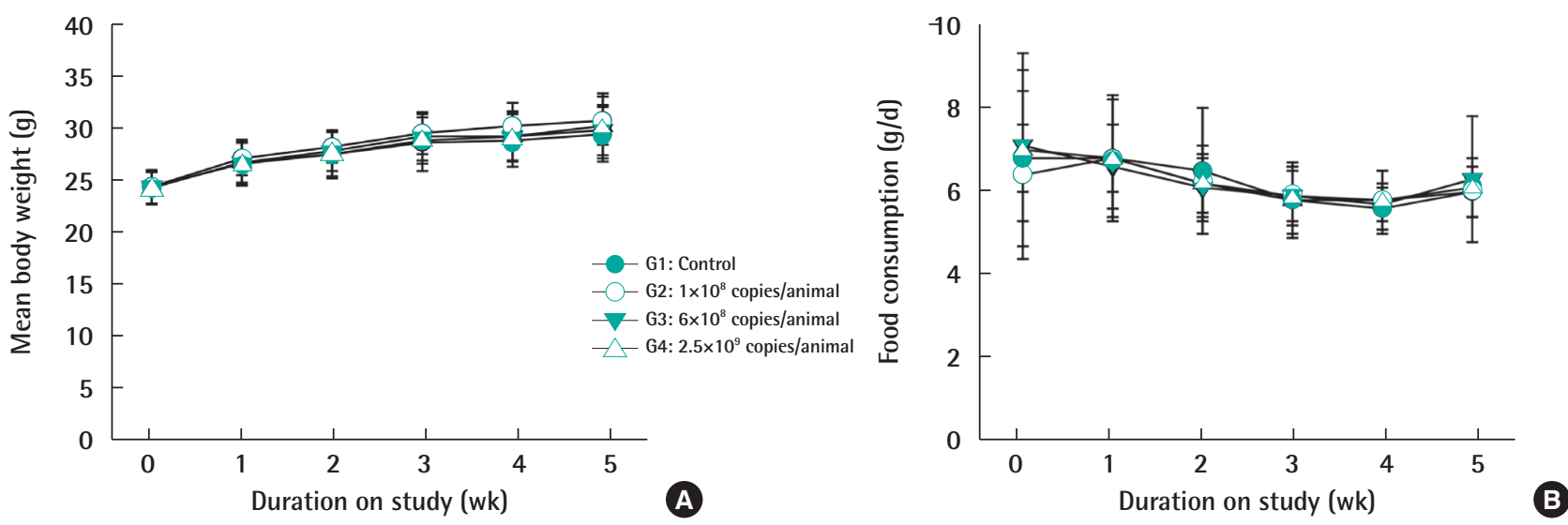

Figure 1. Body weight changes (A) and food consumption (B) in female ICR mice treated with cervical cancer vaccines. Each group consisted of 15 animals, and the results are expressed as mean \pm standard deviation for each group.

Table 2. Hematological parameters in female ICR mice treated with cervical cancer vaccines

\begin{tabular}{|c|c|c|c|c|c|c|c|c|c|c|c|c|c|c|c|}
\hline \multirow[b]{2}{*}{ Group } & \multirow{2}{*}{$\begin{array}{c}\mathrm{RBC} \\
\left(\times 10^{6}\right. \\
\text { cells } / \mu \mathrm{L})\end{array}$} & \multirow[b]{2}{*}{$\begin{array}{c}\mathrm{HGB} \\
(\mathrm{g} / \mathrm{dL})\end{array}$} & \multirow[b]{2}{*}{$\begin{array}{l}\text { HCT } \\
(\%)\end{array}$} & \multicolumn{3}{|c|}{ RBC indices } & \multirow{2}{*}{$\begin{array}{c}\text { PLT } \\
\left(\times 10^{3}\right. \\
\text { cells } / \mu \mathrm{L})\end{array}$} & \multirow{2}{*}{$\begin{array}{c}\text { WBC } \\
\left(\times 10^{3}\right. \\
\text { cells/ } \mu \mathrm{L})\end{array}$} & \multicolumn{5}{|c|}{ Leucocyte differential counting (\%) } & \multirow[b]{2}{*}{$\begin{array}{l}\text { PT } \\
\text { (sec) }\end{array}$} & \multirow[b]{2}{*}{$\begin{array}{l}\text { APTT } \\
\text { (sec) }\end{array}$} \\
\hline & & & & $\begin{array}{l}\text { MCV } \\
\text { (fL) }\end{array}$ & $\begin{array}{c}\mathrm{MCH} \\
(\mathrm{pg})\end{array}$ & $\begin{array}{c}\mathrm{MCHC}(\mathrm{g} / \\
\mathrm{dL})\end{array}$ & & & NUT & LYMPH & MONO & EOS & BASO & & \\
\hline & ) & S & $44.8(3.9)$ & 5 & 1 & 2) & 9) & 2.3 & 16 & 0) & 10 & . & & .4) & $20(1.8)$ \\
\hline G2 & $8.78(0.36)$ & $13.6(0.4)$ & $44.9(2.6)$ & $51.1(2.2)$ & $15.5(0.5)$ & $30.3(1.0)$ & $1,167(318)$ & $2.53(0.86)$ & 15.5 & $80.6(6.1)$ & $3.2(1.1)$ & 0.2( & 0.1 & $9.9(0.4)$ & $38.3(17.6)$ \\
\hline G3 & $8.68(0.92)$ & $13.2(1.2)$ & $43.7(4.8)$ & $50.4(2.5)$ & $15.3(0.7)$ & $30.3(1.5)$ & $1,218($ & ) $2.86(1$ & $15.8(3.8)$ & $80.4(4.8)$ & 2.9 & 0.4 & 0.1 & $9.9(0.2)$ & $25.1(7.6)$ \\
\hline 4 & $8.63(0.45)$ & $13.4(0.7)$ & $44.2(2.7)$ & $51.3(2.8)$ & $15.5(0.6)$ & $30.3(1.4)$ & $1,165(424)$ & $2.39(0.69)$ & $14.8(4.1)$ & $81.4(4.8)$ & $3.1(0.7)$ & 0.3 & $0.1(0.1)$ & $9.9(0.2)$ & $26.9(11$ \\
\hline
\end{tabular}

Values are expressed as mean (SD).

No. of animals in each group $=10$ female mice.

RBC, total red blood cell count; Hgb, hemoglobin concentration; Hct, hematocrit; MCV, mean corpuscular volume; MCH, mean corpuscular hemoglobin; MCHC, mean corpuscular hemoglobin concentration; PLT, platelet; WBC, total white blood cell count; NUT, neutrophils; LYMPH, lymphocytes; MONO, monocytes; EOS, eosinophils; BASO, basophils; PT, prothrombin time; APTT, activated partial thromboplastin time; G1, control group; G2, $1 \times 10^{8}$ copies/animal; G3, 5×108 copies/animal; G4, $2.5 \times 10^{9}$ copies/animal.

Table 3. Biochemical parameters in female ICR mice treated with cervical cancer vaccines

\begin{tabular}{|c|c|c|c|c|c|c|c|c|c|c|c|c|c|c|}
\hline oup & $\begin{array}{l}\text { ALT } \\
\text { (U/L) }\end{array}$ & $\begin{array}{l}\text { ST } \\
\text { /L) }\end{array}$ & $\begin{array}{l}\text { ALP } \\
(\mathrm{U} / \mathrm{L})\end{array}$ & $\begin{array}{c}\mathrm{GLU} \\
(\mathrm{mg} / \mathrm{dL})\end{array}$ & $\begin{array}{r}\mathrm{BU} \\
\text { (mg/ }\end{array}$ & L) & ) & $\begin{array}{l}\mathrm{T}-\mathrm{C} \\
(\mathrm{mg}\end{array}$ & $\begin{array}{c}\mathrm{TG} \\
(\mathrm{mg} / \mathrm{dL})\end{array}$ & $\begin{array}{c}\mathrm{TP} \\
(\mathrm{g} / \mathrm{dL})\end{array}$ & $\begin{array}{c}\text { Alb } \\
\text { (g/dL) }\end{array}$ & $\begin{array}{l}\mathrm{A} / \mathrm{G} \\
\text { ratio }\end{array}$ & $\begin{array}{c}\mathrm{P} \\
(\mathrm{mg} / \mathrm{dL})\end{array}$ & $\begin{array}{c}\mathrm{Ca} \\
(\mathrm{mg} / \mathrm{dL})\end{array}$ \\
\hline & & (1) & & & & 2) & 02) & & & & $0.1)$ & 3) & & \\
\hline & .4) & .7) & 3 & 166 & 18.8 & 03) & 02) & 21) & 6 & 2) & 1.7 & $0.54(0.02)$ & $6.83(1.63)$ & 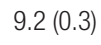 \\
\hline & .5) & $57.7(5.1)$ & ) & 1 & & 03) & .02) & $124(19)$ & 60 & 5.0 & $1.7(0.1)$ & & & $9.3(0$ \\
\hline & $8.5(4.9)$ & $2.9(7.0)$ & $27.0(52.3)$ & 166 (18) & $20.0(3.3)$ & $0.29(0.02)$ & $0.02)$ & $121(25)$ & $56(15$ & $5.1(0.3)$ & 1.7 & $0.50(0.03)^{* * *}$ & $7.38(1.17)$ & $9.2(0$ \\
\hline
\end{tabular}

Values are expressed as mean (SD).

No. of animals in each group $=10$ female mice.

ALT, Alanine aminotransferase; AST, aspartate aminotransferase; ALP, alkaline phosphatase; GLU, glucose; BUN, blood urea nitrogen; Crea, creatinine; T-Bili, total bilirubin; T-Chol, total cholesterol; TG, triglycerides; TP, total protein; Alb, albumin; A/G ratio, albumin-globulin ratio; G1, control group; G2, $1 \times 10^{8}$ copies/animal; G3, $5 \times 10^{8}$ copies/animal; G4, $2.5 \times 10^{9}$ copies/animal.

${ }^{*} p<0.05$ from G1 by Dunnett's $t$-test, ${ }^{* *} p<0.01$ from G2 by Dunnett's $t$-test.

pathological effects, including cystic tubules in the kidney, ectopic thymus in the parathyroid gland, cell infiltration in the salivary gland, and extramedullary hematopoiesis in the spleen. However, these effects were similar when comparing the G1 and G4 groups. In histopathological findings, the animal in G1 showed aplasia of the right uterus horn (Table 4).

\section{Discussion}

Several vaccines targeting high- or low-risk HPV types have been used to protect women from cervical cancer caused by HPV infection. Vaccines have been reported to induce several side effects, including muscle pain or tenderness, seizures, and weakness in clinical trials [9]. Therefore, side effects of newly developed vaccines must be evaluated for safe use of vaccines. 


\begin{tabular}{|c|c|c|c|c|c|}
\hline \multirow{2}{*}{ Organ/findings } & \multirow{2}{*}{ Clinical sign $\left(\mathrm{t} / \mathrm{n}^{\mathrm{a}}\right)$} & \multicolumn{4}{|c|}{ Group } \\
\hline & & G1 & G2 & G3 & G4 \\
\hline \multirow[t]{2}{*}{ Injection sites } & \multirow{2}{*}{$\begin{array}{l}\text { Cell infiltration, mononuclear } \\
\text { Mineralization, myofiber }\end{array}$} & $0 / 10$ & $7 / 10$ & $6 / 10$ & $6 / 10$ \\
\hline & & $0 / 10$ & $0 / 10$ & $0 / 10$ & $2 / 10$ \\
\hline Kidney & \multirow[t]{2}{*}{ Cystic tubules, cortical } & $1 / 10$ & - & - & $0 / 10$ \\
\hline Liver & & $0 / 10$ & - & - & $0 / 10$ \\
\hline Parathyroid & Ectopic thymus & 01/09 & - & - & $0 / 7$ \\
\hline Salivary gland, submandibular & Cell infiltration, lymphocytic, focal & $01 / 10$ & - & - & $0 / 10$ \\
\hline Spleen & Extramedullary hematopoiesis & $10 / 10$ & - & - & $9 / 10$ \\
\hline \multirow[t]{2}{*}{ Thyroid } & \multirow{2}{*}{$\begin{array}{l}\text { Dilatation, follicular, } \\
\text { focal Ectopic thymus }\end{array}$} & $1 / 10$ & - & - & $0 / 10$ \\
\hline & & $01 / 10$ & - & - & $1 / 10$ \\
\hline Uterus & Aplasia, right horn & $0 / 10$ & $\left(1 / 1^{b}\right)$ & - & $0 / 10$ \\
\hline
\end{tabular}

G1, control group; G2, $1 \times 10^{8}$ copies/animal; G3, $5 \times 10^{8}$ copies/animal; G4, $2.5 \times 10^{9}$ copies/animal.

${ }^{a}$ No. of animals with signs of toxicity divided by no. of examined animals; ${ }^{b H i s t o p a t h o l o g i c a l ~ e f f e c t s ~ i n ~ o n e ~ a n i m a l ~ s h o w n ~ a p l a s i a ~ i n ~ u t e r u s ~ a p l a s i a ~ b y ~ n e c r o p s y . ~}$

We developed two new vaccines (Ac-HERV-16-58-18 L1 and Ac-HERV-LAMPss-E6E7) for cervical intraepithelial neoplasia grade 2/3 (CIN2 and CIN3). Two recombinant baculovirus constructs, Ac-HERV-16-58-18 L1 and Ac-HERV-LAMPssE6E7, deliver the HERV env and HPV16/58/18 L1 genes and HPV16 E6/E7 to allow transduction of the HPV16/58/18 L1 gene and the HPV16 E6/E7, respectively. In this study, we evaluated the sub-acute toxic effects of the vaccines targeting HPV 16/58/18 and HPV 16. Female ICR mice were treated with a 1:1 mixture of two vaccines (Ac-HERV-16-58-18 L1 and AcHERV-LAMPss-E6E7) by repetitive muscular injection once a week for 5 weeks.

Female mice exposed to low, middle, and high doses $\left(1 \times 10^{8}\right.$, $5 \times 10^{8}$, and $2.5 \times 10^{9}$ copies/animal) cervical cancer vaccine did not show mortality, morbidity, or clinical signs (data not shown).

In serum biochemical parameters, only the $\mathrm{A} / \mathrm{G}$ ratio showed a significant change in all treated groups compared to the control group (Table 3). In some biochemical parameters related to liver (ALT, AST, ALP, and T-Bili) and kidney (BUN, Crea, and T-Bili) function, vaccines did not induce a significant change in the vaccine-treated groups. In addition, in urinalysis (data not shown), necropsy (data not shown), and histopathological effects (Table 4) in the kidney and liver, the vaccines had no distinct toxic symptoms. Therefore, we suggest that the tested vaccines may not induce any toxic responses in the kidney and liver function. The two major proteins in blood, albumin and globulin, are produced in the liver. In this study, the tested vaccines did not show any changes in albumin level (Table 3). However, the $A / G$ ratio was significantly decreased in a dose-dependent manner. We suggest that the decrease in the $\mathrm{A} / \mathrm{G}$ ratio was due to the response to elevated globulins. Although the $\mathrm{A} / \mathrm{G}$ ratio is not a specific marker for disease, it has been used as an index of disease state. In particular, a decrease in the $\mathrm{A} / \mathrm{G}$ ratio due to in- creased globulin can be induced by some inflammatory diseases, multiple myeloma, collagen disease, and rheumatoid arthritis (http://labtestsonline.org/understanding/analytes/tp/tab/ test/). However, although the $\mathrm{A} / \mathrm{G}$ ratio was significantly decreased in a dose-dependent manner, all values were within normal ranges (0.52-0.62 in ICR mice of 11-12 weeks). In addition, the related pathological symptoms were not present in all treated groups. Therefore, we suggest that the decrease in the $A / G$ ratio in this study may not be considered non-adverse.

Muscular injection of vaccines has been reported to induce mild to moderate injection site symptoms, such as redness, bruising, itching, swelling, pain, and cellulitis [9]. In this study, several female mice exposed to vaccines showed mononuclear cell infiltration at the injection site in all treated groups. In addition, two of 10 mice exposed to high-dose vaccines showed myofiber mineralization. However, because these symptoms could be disappeared and recovered according to stop of injection, we suggest that it could not be considered to be toxic effect to be maintained continuously by vaccine injection.

Some examined animals in the control group showed histopathological effects, such as cystic tubules in the kidney cortex, ectopic thymus in the parathyroid gland, cell infiltration, lymphocytic, focal in salivary gland, dilation, follicular, ectopic thymus in thyroid. However, only one animal exposed to vaccines showed focal ectopic thymus in the thyroid gland, and other histopathological effects were not present in female mice of G1 and G4. In addition, extramedullary hematopoiesis in the spleen was found in both control and high-dose groups (Table 4). Extramedullary hematopoiesis is the normal response during fetal development and can induce an increase in spleen size [17]. In the control and all treated groups, the absolute and relative weight of the spleen did not show any changes (Table 1). Chunduri et al. [18] also reported that extramedullary hematopoiesis 
can be caused by pathologic processes, such as pulmonary myelofibrosis. However, in this study, all female mice in the control and vaccine-treated groups did not show the related pathologic symptoms. Therefore, the histopathological effects may not be a toxic response caused by vaccine injection.

In conclusion, vaccines targeting high-risk HPV types 16, 58, and 18 did not show any toxicological symptoms for body weight, absolute/relative organ weight, hematological/biochemical parameters, or histopathological parameters in any treated group. In addition, $2.5 \times 10^{9}$ copies/animal, high exposure dose tested in this study was more than 8,300 fold of expected clinical injection dose, $1 \times 10^{10}$ copies/human. Therefore, the tested vaccines may not induce toxic signs at the expected clinical injection dose. Finally, we suggest that the NOAEL of the vaccine following repetitive intramuscular injection for 5 weeks is $>2.5 \times 10^{9}$ copies/animal.

\section{Acknowledgements}

This work was supported by Kolon Life Science Co., Ltd.

\section{Conflict of Interest}

The authors have no conflicts of interest with material presented in this paper.

\section{References}

1. Clifford GM, Smith JS, Plummer M, Muñoz N, Franceschi S. Human papillomavirus types in invasive cervical cancer worldwide: a meta-analysis. Br J Cancer 2003;88(1):63-73.

2. Lee GH, Kang HJ, Kim SY, Park CM. The prevalence of human papilloma virus infections according to Pap smear results in Jeju island. Korean J Obstet Gynecol 2011;54(11):689-695 (Korean).

3. Division of STD Prevention. Prevention of genital HPV infection and sequelae: report of an external consultants' meeting [cited 2014 Oct 14]. Available from: http://www.cdc.gov/std/hpv/hpvsupplement99.pdf.

4. Baudu A, Prétet JL, Riethmuller D, Chotard M, Mougin C, Mercier $\mathrm{M}$. Prevalence and risk factors of human papillomavirus infection types 16/18/45 in a cohort of French females aged $15-23$ years. J Epidemiol Glob Health 2014;4(1):35-43.

5. Chen Q Xie LX, Qing ZR, Li LJ, Luo ZY, Lin M, et al. Epidemio- logic characterization of human papillomavirus infection in rural Chaozhou, eastern Guangdong Province of China. PLoS One 2012; 7(2):e32149.

6. Mishra GA, Pimple SA, Shastri SS. An overview of prevention and early detection of cervical cancers. Indian J Med Paediatr Oncol 2011;32(3):125-132.

7. Herrero R. Human papillomavirus (HPV) vaccines: limited crossprotection against additional HPV types. J Infect Dis 2009;199(7): 919-922.

8. Kim KS, Park SA, Ko KN, Yi S, Cho YJ. Current status of human papillomavirus vaccines. Clin Exp Vaccine Res 2014;3(2):168-175.

9. Schiller JT, Castellsagué X, Garland SM. A review of clinical trials of human papillomavirus prophylactic vaccines. Vaccine 2012;30 Suppl 5:F123-F138.

10. Palefsky JM, Giuliano AR, Goldstone S, Moreira ED Jr, Aranda C, Jessen $\mathrm{H}$, et al. HPV vaccine against anal HPV infection and anal intraepithelial neoplasia. N Engl J Med 2011;365(17):1576-1585.

11. FuturE II Study Group. Quadrivalent vaccine against human papillomavirus to prevent high-grade cervical lesions. N Engl J Med 2007;356(19):1915-1927.

12. Paavonen J, Naud P, Salmerón J, Wheeler CM, Chow SN, Apter D, et al. Efficacy of human papillomavirus (HPV)-16/18 AS04-adjuvanted vaccine against cervical infection and precancer caused by oncogenic HPV types (PATRICIA): final analysis of a doubleblind, randomised study in young women. Lancet 2009;374(9686): 301-314.

13. Garland SM, Hernandez-Avila M, Wheeler CM, Perez G, Harper DM, Leodolter S, et al. Quadrivalent vaccine against human papillomavirus to prevent anogenital diseases. N Engl J Med 2007;356 (19):1928-1943.

14. Giuliano AR, Palefsky JM, Goldstone S, Moreira ED Jr, Penny ME, Aranda $\mathrm{C}$, et al. Efficacy of quadrivalent $\mathrm{HPV}$ vaccine against $\mathrm{HPV}$ infection and disease in males. N Engl J Med 2011;364(5):401411.

15. Slade BA, Leidel L, Vellozzi C, Woo EJ, Hua W, Sutherland A, et al. Postlicensure safety surveillance for quadrivalent human papillomavirus recombinant vaccine. JAMA 2009;302(7):750-757.

16. Block SL, Brown DR, Chatterjee A, Gold MA, Sings HL, Meibohm A, et al. Clinical trial and post-licensure safety profile of a prophylactic human papillomavirus (types 6, 11, 16, and 18) 11 virus-like particle vaccine. Pediatr Infect Dis J 2010;29(2):95-101.

17. Georgiades CS, Neyman EG, Francis IR, Sneider MB, Fishman EK. Typical and atypical presentations of extramedullary hemopoiesis. AJR Am J Roentgenol 2002;179(5):1239-1243.

18. Chunduri S, Gaitonde S, Ciurea SO, Hoffman R, Rondelli D. Pulmonary extramedullary hematopoiesis in patients with myelofibrosis undergoing allogeneic stem cell transplantation. Haematologica 2008;93(10):1593-1595. 